\title{
Diagnosis and Management of Field Pollution in the Case of an Organochlorine Pesticide, the Chlordecone
}

\author{
T. Woignier, F. Clostre, P. Cattan, J. Levillain, \\ Y.M. Cabidoche and M. Lesueur-Jannoyer \\ Additional information is available at the end of the chapter \\ http://dx.doi.org/10.5772/57263
}

\section{Introduction}

\subsection{Background}

The consequences of pesticide pollution of soil and water can be extremely damaging for both the environment and human health. Chlordecone (CLD), an organochlorine insecticide $\left(\mathrm{C}_{10} \mathrm{Cl}_{10} \mathrm{O}\right)$, was used to control the banana black weevil more than twenty years ago in the French West Indies but continues to contaminate the environment today [1, 2]. CLD pollution occurs in many parts of the world [3-5] and CLD is very persistent, sorptive and highly lipophilic [6]. Its persistence in soils is due to its low solubility in water [7], high affinity for organic matter with a $K_{o c}$ (soil organic carbon content/water partitioning coefficient) of between 2.5 and $20 \mathrm{~m}^{3} \mathrm{~kg}^{-1}[1,8]$, and to its chemical structure (Figure1), which makes it poorly biodegradable [9]. Similar characteristics are shared by all organochlorine pesticides and persistent organic pollutants.

CLD causes diffuse pollution in agricultural soils [10], which in turn become a continuous source of contamination for water resources, crops and animals [1, 3, 11, 12]. In addition, its long-term effects on human health and child development linked to the consumption of polluted food and water are now a serious concern [13-15].

\subsection{Objective}

This chapter explores the multifactorial nature of soil pollution and its evolution at field and regional scale. We focus on two key factors that determine CLD contamination and dispersion in ecosystems. One is physical and the other anthropogenic. The first is the influence of clay microstructure on (1) the concentration of CLD in the soil, (2) the bioavailability of the 
pollutant for crops and water resources, and (3) the efficiency of the remediation process. The second factor is past and present farming practices through their effects on (1) the stock of pollutant and its components in the soil and its distribution at the plot and regional scales, and (2) the diffusion of the pollutant in the different compartments of the environment. These two factors determine the contributing areas and their pollutant stock, the potential availability and fluxes of the pollutant, and hence its potential transfer to different environmental compartments.

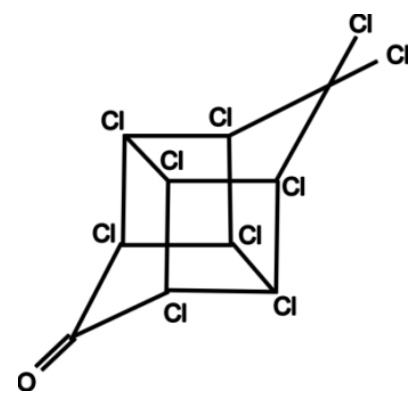

Figure 1. The chlordecone molecule $\left(\mathrm{C}_{10} \mathrm{Cl}{ }_{10} \mathrm{O}\right)$

\section{Influence of clay microstructure}

The studied soils come from Guadeloupe $\left(16^{\circ} 15 \mathrm{~N}, 61^{\circ} 35 \mathrm{~W}\right)$ and Martinique $\left(14^{\circ} 40 \mathrm{~N}, 61^{\circ} 00\right.$ $\mathrm{W})$ in the French West Indies. These volcanic islands rise to $1467 \mathrm{~m}$ and $1388 \mathrm{~m}$ elevation respectively. Rainfall is high and ranges from 1000 to $10000 \mathrm{~mm} /$ year depending on the elevation and geographical area. All primary minerals of andesitic rocks are weathered, so that soils have a high content of secondary minerals (clays): halloysite for nitisol, halloysite and Fe-oxihydroxides for ferralsol, and allophane for andosol, the three main soil types contaminated in French West Indies [1, 10, 16].

These volcanic soils have a high infiltration capacity (saturated hydraulic conductivity greater than $60 \mathrm{~mm} \mathrm{~h}^{-1}$ ) [1, 10]. However in the "clay" matrix of andosols, there are pores smaller than 1 micron, where water and solute transfers are slow. All these soil types are acidic $(\mathrm{pH}=4.5-6)$, which prevents clay dispersion and sheet erosion [1]. Among these soils, the carbon content of andosol is particularly high, which may influence the retention of the compound (stock) and its availability.

Indeed all soils are not equivalent in terms of pesticide contamination and in their ability to transfer the pollutant to water and to plants [17, 18]. For example, although andosols are highly polluted $[1,10,16]$, data show they release less pesticide to percolating water and crops than other soils $[1,19]$. In the case of CLD, one explanation for the retention effect reported in the literature is the high organic content of these soils and the high affinity of the pesticide for soil organic carbon $[1,8]$. 
However, these volcanic soils contain amorphous clay, allophane, whose structure and physical properties differ from those of the crystalline clays found in nitisols and ferralsols. Allophane clay is amorphous and has physical features that closely resemble those of nano porous materials: large pore volume and water content, a broad pore size distribution, a high specific surface area and a fractal structure [20-22]. One objective of this chapter is to show the influence of the clay microstructure on the accumulation and retention of chlordecone in soils.

\subsection{Allophane microstructure}

Figure 2 shows the pore volume and specific surface area as a function of the allophane content of a set of andosols. There was a clear increase in these two textural features with an increase in allophane content, showing that allophane clay favors larger porous features. The pore volume and the specific surface area were well correlated with allophane content (respectively $\mathrm{P}<0.0001 \mathrm{r}^{2}=0.87$ and $\mathrm{P}<0.0001, \mathrm{r}^{2}=0.80$ ). The specific surface area was as high as $180 \mathrm{~m}^{2} \cdot \mathrm{g}^{-1}$ and pore volume close to $2.5 \mathrm{~cm}^{3} \cdot \mathrm{g}^{-1}$. This combination of high specific surface area and large pore volume suggests that the porous structure is made up of both microand mesopores.

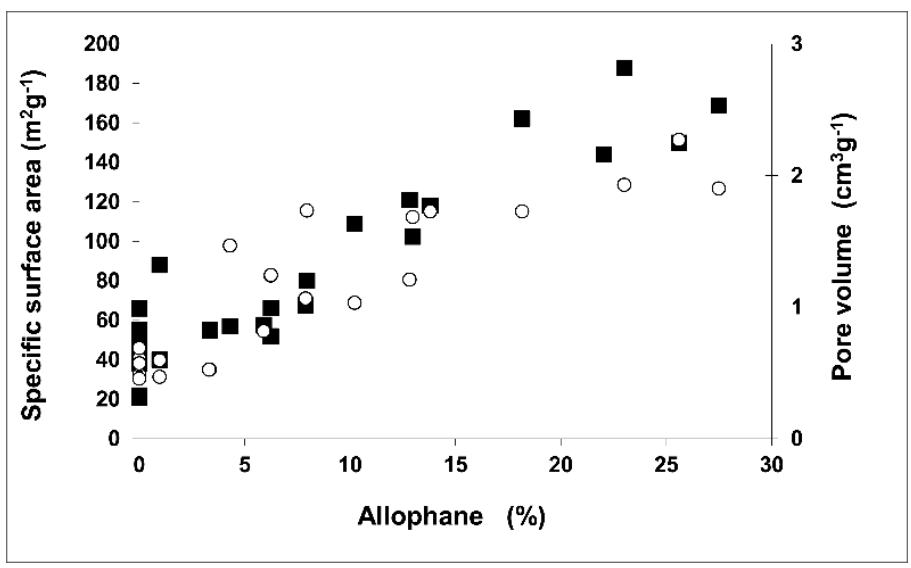

Figure 2. Pore volume (empty circles, o) and specific surface area (black squares, $\mathbf{a})$ versus allophane content

Figure 3 shows the structure of amorphous clay in comparison with classical phyllosilicate clay: kaolinite or halloysite. These micrographs confirm the spongy structure of allophane clay.

The morphology of the allophane aggregates is peculiar [21]. Allophane has a very open structure made up of aggregated small particles $(3-5 \mathrm{~nm})$ that form clusters of around 10-20 $\mathrm{nm}$. The clusters can stick together and form larger and larger aggregates up to $\sim 100 \mathrm{~nm}$ in size. In comparison, the plate-like particles of phyllosilicate clay are 300-1000 $\mathrm{nm}$ in size (Figure 3). This aggregation mechanism is in agreement with results in the literature [22, 24]. 


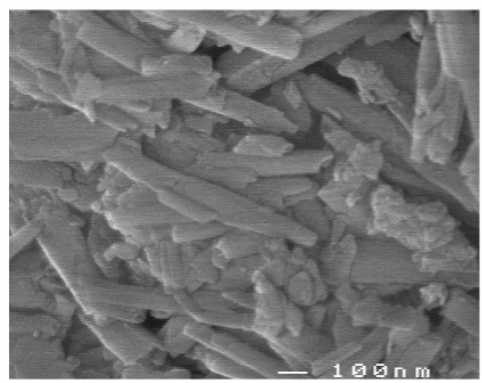

Phyllosilicate clay (halloysite or kaolinite)

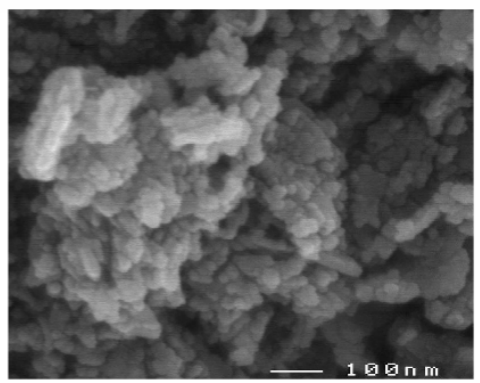

Allophanic clay

Figure 3. Scanning electronic micrographs showing the structure of phyllosilicate clay and amorphous clay from [23]

Wada [22] describes allophane particles as nearly spherical, with diameters ranging from 3-5 $\mathrm{nm}$. The aggregation mechanism corresponds to a fractal morphology. Several authors assumed that allophane could have a fractal structure [20,22]. The structure of allophane can be studied at nanoscale using scattering experiments to quantify the fractal features of the soil samples. Small angle X-ray scattering (SAXS) experiments make it possible to calculate the fractal dimension $D_{f}$ (which expresses the compactness and tortuosity of the clusters) and the extent of the fractal aggregates $(\xi)$ [25]. The fractal extent can be considered as the size of the tortuous "nano-labyrinth". SAXS curves [26] show that the fractal dimension $D_{f}$ is constant (2.5-2.7). Table 1 lists changes in $\xi$ versus allophane content. Our results showed that the size of the fractal labyrinth increased with an increase in allophane content $(\mathrm{P}=0.001$ and $\mathrm{r}^{2}=0.71$ ).

\begin{tabular}{lcccccccccc}
\hline Allophane (\%) & 0 & 3 & 5 & 8 & 10 & 12 & 13 & 15 & 18 & 22 \\
\hline$\xi(\mathrm{nm})$ & 0 & 12 & 23 & $22-32$ & 18 & $23-35$ & 23 & 35 & $34-45$ & $42-60$ \\
\hline
\end{tabular}

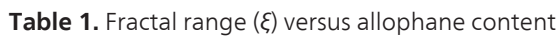

These data (high specific surface area and pore volume, and fractal features) describe a highly tortuous microstructure and small mesopores, suggesting that accessibility inside the clay microstructure is reduced.

\subsection{Pesticide sequestration in allophane}

Allophane clay has a spongy structure comprising aggregated small particles that form a tortuous network with small pores. This peculiar structure influences the concentration of pesticide in the soil.

Figure 4 shows the marked increase in CLD concentration in soils with increasing allophane content $\left(\mathrm{P}<0.0001\right.$ and $\left.\mathrm{r}^{2}=0.807\right)$. This finding confirms previous data in the literature $[1,16$, 27] stating that allophanic soils are more contaminated than other kinds of tropical soils, 


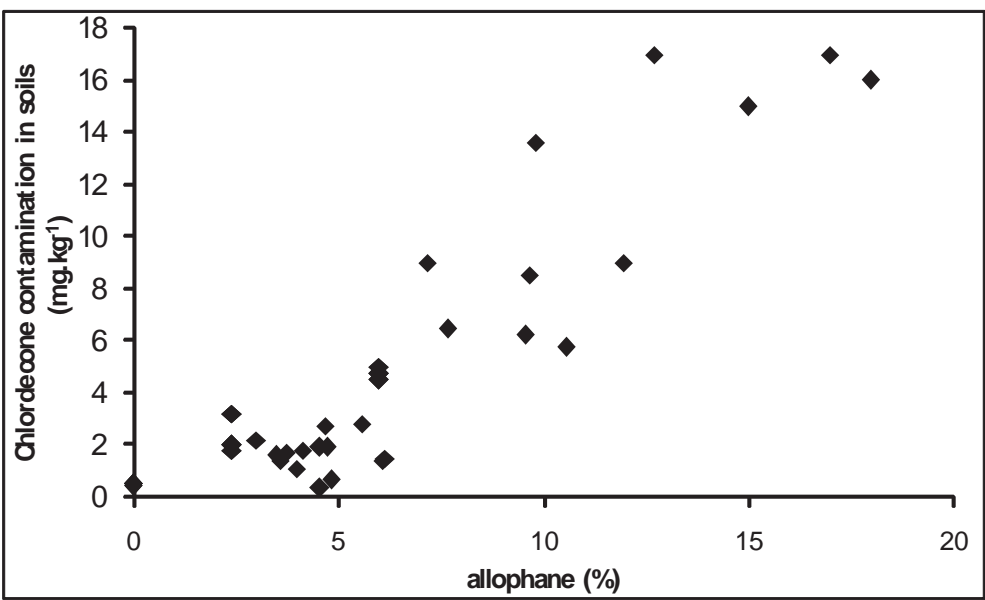

Figure 4. Soil CLD contamination versus allophane content. CLD data have a confidence interval of $30 \%$

which contain the usual crystalline clays (like halloysite and kaolinite). Figure 4 also clearly shows the link between CLD contamination of the soil and the allophane content of the soil and one can thus assume that the pesticide retention properties of the soil are partially dependent on the features of allophane.

Another interesting result of our previous study was that for similar soil CLD contents, crops cultivated on allophanic soils were much less contaminated than the same crops cultivated on soils containing classical clays, [26]. We calculated the mean soil to plant transfer (expressed in $\mu \mathrm{g} \cdot \mathrm{kg}^{-1}$ of fresh matter $/ \mu \mathrm{g} \cdot \mathrm{kg}^{-1}$ of dry soil), for different crops. Table 2 confirms that, whatever the crop concerned [26], CLD soil to plant transfer was always higher in halloysite soils than in allophanic soils. For the three crops studied (lettuce, yam, and dasheen) the ratio was close to 3 .

\begin{tabular}{cccc}
\hline Crops & $\begin{array}{c}\text { Soil to crop transfer } \\
\text { (halloysite soils) }\end{array}$ & $\begin{array}{c}\text { Soil to crop transfer } \\
\text { (allophanic soils) }\end{array}$ & $\begin{array}{c}\text { Ratio } \\
\text { (halloysite: allophanic) }\end{array}$ \\
\hline Lettuce & $0.64(0.14)$ & $0.23(0.15)$ & 2.83 \\
Yam & $3.2(2.1)$ & $1.04(0.75)$ & 3.13 \\
Dasheen & $12.2(5.8)$ & $3.26(2.56)$ & 3.73 \\
\hline
\end{tabular}

Table 2. Mean CLD transfers from halloysite and allophanic soils to lettuce, yam and dasheen, expressed in $\mu \mathrm{g} . \mathrm{kg}^{-1}$ of fresh matter / $\mu \mathrm{g} \cdot \mathrm{kg}^{-1}$ of dry soil (standard deviation in brackets) [26]

\subsection{Trapping mechanism in allophane}

The results shown in Figure 4 and Table 2 may appear contradictory because one would expect allophanic soils, which are more contaminated, to strongly pollute cultivated vegeta- 
bles. One explanation for the observed effect is that CLD is trapped in the microstructure of the allophane clay, thus reducing its transfer from the soil to the plant. The influence of soil allophane content on CLD retention is the signature of the peculiar microstructure of the allophane aggregate. The spongy structure influences transport inside the allophane aggregates. The SAXS data made it possible for us to propose a mechanism for the retention of pesticides in allophanic soils and also for the limited release of CLD to crops and water resources [1, 19]. At the scale of the allophane, accessibility is difficult because of the fractal structure and small pore size of allophane clay. CLD transfers within the soil depend on hydraulic conductivity $(K)$ and diffusion processes $(D i)$ in the porous microstructure. The fractal structure allows an approximation of $K$ and $D i$ at the aggregates scale $l$ [26] through the following equations:

$$
\left.K(l) \infty\left[1-[l / a]^{D f-3}\right] / l^{2} \text { and } D i \infty\left(1-(l / a)^{D f-3}\right)\left[1-2 / 3\left(2-(l / a)^{D f-3}\right)(l / a)^{D f-3}\right)^{3 / 2}\right] .
$$

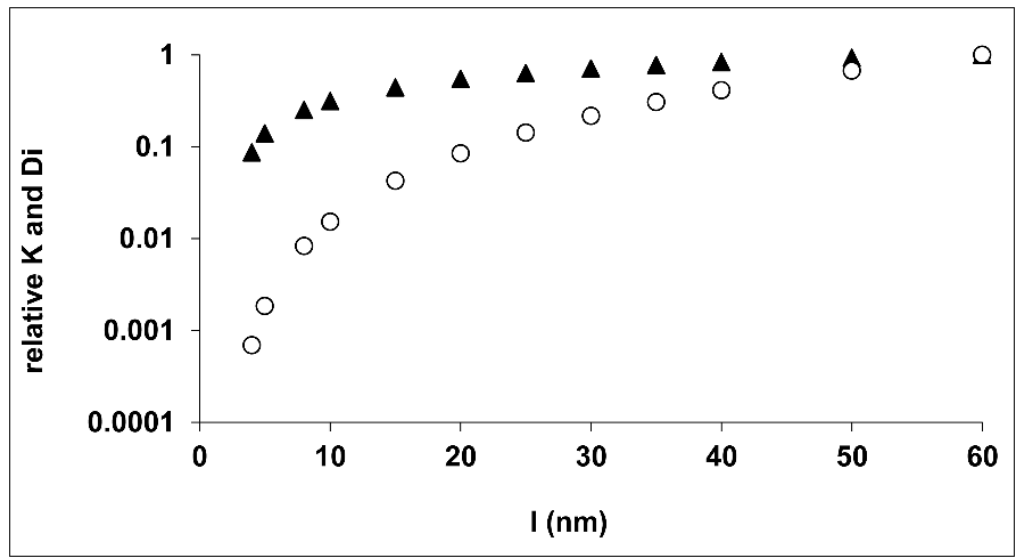

Figure 5. Relative $\mathrm{K}(\mathrm{O})$ and $\mathrm{Di}(\boldsymbol{\Lambda})$ versus the scale length, I (nm)

We calculated the transport properties (hydraulic conductivity and diffusion, inside the allophane fractal aggregate, i.e. between 3 and $60 \mathrm{~nm}$ (Table 2). Figure 5 shows changes in $K$ and $D i$ normalized to $K$ and $D i$ at $l=60 \mathrm{~nm}$. Hydraulic conductivity decreased by 4 orders of magnitude and $D i$ decreased by 20 orders of magnitude when $l$ decreased from 60 to $4 \mathrm{~nm}$.

The very low calculated $D i$ and $K$ suggest that CLD is trapped in the porosity. The trapping mechanism is favored by the large size of the fractal labyrinth. The higher the allophane content, the bigger the labyrinth and the higher the retention. Like nanoporous materials [28], the paradox of allophane clay is that it has large porosity but poor transport properties. In these fractal structures, possible reactions with chemical or biological species that could extract the pesticides are thus hindered; the pesticide remains trapped inside allophane clay and cannot be extracted. 


\subsection{Influence of allophane on the decontamination process}

Soil features influence pollutant availability and hence natural decontamination of the soil. In the case of CLD and other organochlorine pesticides, natural decontamination is very slow, and pollution management and remediation have to take into account any soil properties that could influence the efficiency of the treatment considered [1].

Although different strategies are proposed in the literature to remediate diffuse pollution of CLD including phytoextraction [29] and microbial degradation [30, 31], to date, these approaches have not been very successful. Recently "In situ chemical reduction" was tested for the reduction of the pesticide in the soil [32], but the technique was clearly less efficient in soils containing allophane clay. Six months of in situ chemical reduction resulted in an $88 \%$ decrease in CLD content in halloysite soils but only in a $47 \%$ decrease in allophanic soils. The efficiency of the in situ chemical reduction technique was probably affected by poor accessibility to the allophane clusters. Trapping thus likely reduces the degradation of pesticides in andosols. Whatever the soil decontamination process used to desorb or degrade the CLD, the confining structure of the clay has to be taken into account to ensure the process is effective.

\section{Key farming practices}

Soil type determines the potential for CLD sequestration but, in the analysis of risk and in the diagnosis of soil pollution, farming practices are key factors that determine the level of the pollutant stock, its potential availability, and its potential transfer to different environmental compartments [1, 10,33]. In this section, we examine the effect of three main types of practices characteristic of past and present farming practices. The first is the level of intensification of the cropping system, which, in the case of CLD, determines the initial input $[1,10$, 33]. The second is soil tillage, which determines the depth (and hence the volume) of soil affected by the pollution [1, 10,33]. The third is organic matter amendment, which affects the availability of CLD [34].

\subsection{Level of intensification of the cropping system}

It is a truism to say that soils are polluted because they have received pollutants. Farmers use a wide range of strategies based on pesticides to protect their crops. These strategies mainly depend on the intensification of the cropping system [35-37]. Intensive systems produce a higher cash flow and more profit than small diversified systems [38, 39] and farmers tend to minimize the risk of yield loss by intensifying chemical pest control [10]. These farmers have to deal with higher pest pressure than systems that include crop rotation and diversification, and consequently require more frequent treatments [40, 41]. In agro-industrial banana plantations in the French West Indies, agronomic and economic conditions led to the intensive use of agrochemicals [39] i.e. frequent applications and/or high doses of the persistent molecule CLD over large areas. In 2013, twenty years after the treatments ended, the 
ubiquitous presence of the CLD in different environmental compartments raises the question of the impact of these past applications on soil contamination and its true extent.

To answer this question, the link between CLD supply and soil contamination was first examined using a simple CLD leaching model called WISORCH [1]. This model predicts soil CLD content based on the history of CLD applications under different farming systems, different soil types, and different average annual rainfalls. The model accounts for andosol, nitisol and ferralsol through their main characteristics, notably the soil-water partition coefficient relative to organic $C$ content $\left(K_{o c}\right.$ in $\left.\mathrm{m}^{3} \mathrm{~kg}^{-1}\right)$, soil organic carbon content, depth of tillage and soil bulk density.

Simulation results first showed that the schedule of CLD applications, i.e. CLD loads, had the most impact. Long after the application of CLD, the effect of CLD loads on soil CLD content meant that soil decontamination was extremely slow. By exploring different assumptions, the WISORCH model provided two main explanations for the slowness of decontamination: 1) the absence of degradation; 2) only lixiviation by percolation water can slowly reduce soil contamination. These assumptions are consistent with the lack of evidence for natural degradation of CLD reported in the literature [9]; given the very low volatility of CLD, water is the only vector of CLD dispersion.

In addition to the main effect of CLD applications, WISORCH simulations identified tillage depth as the second factor that influences soil CLD content. This factor depends on cropping systems and is discussed below. Here we simply note that physical factors like soil gravimetric carbon content, bulk density and average annual rainfall have less impact. Consequently, human activity was the first determinant of soil contamination.

The WISORCH model explained why large areas are still contaminated even though treatments were halted long ago. As the model first identified the schedule of pesticide applications, this suggested that tracing the history of these applications would help assess the level and distribution of soil contamination at a regional scale. A historical analysis was performed in Guadeloupe using maps of banana plantations at different dates. The results revealed three gradients of land use for banana in 1145 plots (1 $376 \mathrm{ha}$ ) that were analyzed for the presence of CLD [10].

Overall, plot contamination increased with the duration of land use in andosols and ferralsols. Table 3 shows that on average, plots with short term banana land use were less contaminated than those with medium and long term use. The lack of a significant difference between medium and long term banana land use in CLD stocks and concentrations was consistent with the widespread use of CLD in the 1980s and the 1990s, but this was not the case in the 1970s, when CLD was used frequently but not systematically. The effect of banana land use duration was significant for andosols and ferralsols but not for nitisols. This difference in behavior between soils could be explained by their ability to retain CLD. In this case, unlike andosols and ferralsols, the lower retention capacity of nitisols could mask the impact of variations in CLD inputs with respect to the length of time the land was used for banana cultivation. 


\begin{tabular}{|c|c|c|c|c|}
\hline \multirow[b]{2}{*}{$\log ([C L D])$} & \multicolumn{3}{|c|}{ Land use duration } & \multirow[b]{2}{*}{ Mean soil } \\
\hline & Short & Medium & Long & \\
\hline \multirow[t]{2}{*}{ Andosol } & $0.87 a$ & $1.14 b$ & $1.16 \mathrm{~b}$ & $1.11 \mathrm{c}$ \\
\hline & (1.39) & $(2.13)$ & $(2.19)$ & $(2.05)$ \\
\hline \multirow[t]{2}{*}{ Ferralsol } & $0.25 a$ & $0.52 b$ & $0.38 a b$ & $0.45 a$ \\
\hline & $(0.28)$ & $(0.69)$ & $(0.46)$ & $(0.57)$ \\
\hline \multirow[t]{2}{*}{ Nitisol } & $0.62 a$ & $0.66 a$ & $0.64 a$ & $0.65 b$ \\
\hline & $(0.86)$ & $(0.94)$ & $(0.89)$ & $(0.91)$ \\
\hline \multirow[t]{2}{*}{ Mean duration } & $0.64 a$ & $0.91 b$ & $0.91 b$ & \\
\hline & (0.9) & $(1.48)$ & (1.48) & \\
\hline
\end{tabular}

Table 3. Effect of soil type and banana land use duration (short, medium and long term) on the log of mean soil CLD concentration (corresponding values in mg kg-1 in brackets). Differences in means were assessed at two levels: globally, for the "mean soil" column and "mean duration" rows (in italics); for each soil, i.e. each row (in normal font). For each case, the letters $a, b$ and $c$ indicate significant differences between factor levels at $p<0.05$ (Kruskal-Wallis test). [10]

The soil sorption capacity was first assessed by inverting the WISORCH model [1] to determine $K_{o c}$. Results showed that andosols had a higher sorption capacity ( $K_{o c}$ of 12-25) than ferralsols $\left(K_{o c}\right.$ of 7.5-12) and nitisols $\left(K_{o c}\right.$ of 2-3).

This is consistent with our previous results concerning CLD sorption. Indeed, these differences in $K_{o c}$ do not stem from the chemical composition of the clays, since the allophane in andosols does not significantly differ from phyllosilicate clays (nitisols and ferralsols) [42]. The higher apparent $K_{o c}$ in andosols could be the result of the allophane microstructure, leading to lower CLD availability.

Moreover, large farms were more contaminated than small farms [10]. We selected farms with more than 10 plots to assess the intra-farm variation in CLD concentrations. Figure 6 shows that inter-farm variation in CLD concentration was far higher than the intra-farm variation whatever the soil type, meaning the farm factor was decisive in explaining the distribution of CLD concentration. Regardless of the type of soil, the treatment strategy used on a given farm was an essential component of soil contamination.

Concerning the type of soil and other physical factors of CLD retention in soils, at regional scale, the effect of the type of soil was clear. Analysis of CLD concentrations (Table 2) revealed significant differences between soils ( $\mathrm{p}<0.05$ Kruskal-Wallis test) showing that andosols were the most contaminated. Values of CLD concentrations in andosols were 2.3-fold higher than in nitisols, and 3.6-fold higher than in ferralsols. Organic carbon (OC) content was only calculated for andosols to avoid possible interactions with other physical variables (notably, allophane). Results showed that andosols with high OC content tended to retain CLD better. However, the relationship was weak. A probable explanation is that OC had less impact due to the variability of inputs. Finally, although carbon is considered to deter- 


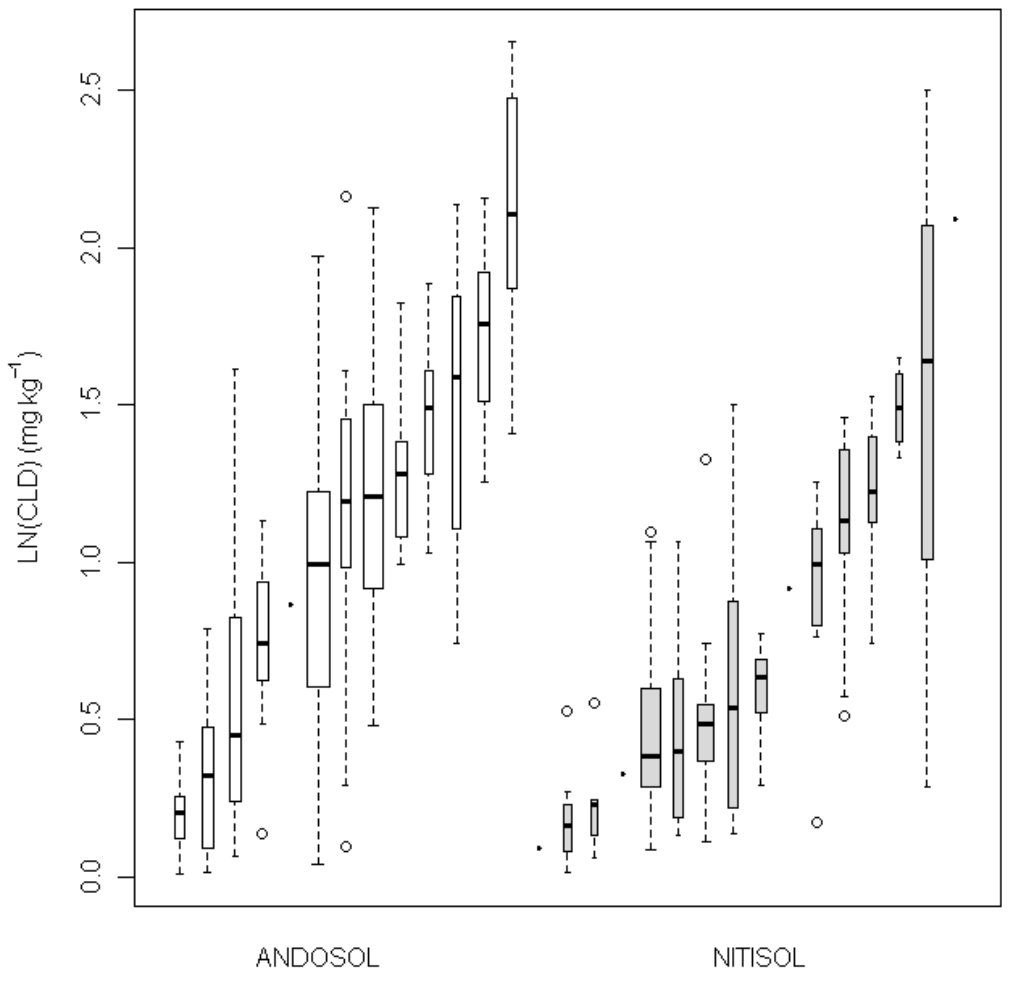

Farms

Figure 6. Distribution of CLD concentration on farms located on andosols and nitisols with more than 10 banana plots. Each box represents a farm. The bottoms and tops of the boxes represent the 25th and 75th percentile; the band inside the box is the median; the whiskers extend to the most extreme data point, which is no more than 1.5 times the interquartile range of the box [10].

mine sorption of CLD, at the regional scale, organic carbon was not a prime factor in explaining variations in CLD concentrations.

To summarize, findings at the regional scale were consistent with the findings of the WISORCH model at the plot scale. Farming systems mainly explained soil CLD contamination, and physical factors like soil carbon content had less influence. Concerning the type of soil, although the findings were the result of observations at different scales - region, plot, microstructure - they all highlighted the specific sorption capacity of andosols for CLD.

These important observations made it possible to draw maps of areas with a risk of CLD contamination in Guadeloupe and Martinique based on soil type and on an historical analysis of the supply of CLD [43,44]. They also identified a pollution system characterized by remarkable inertia comprising (i) a persistent molecule - CLD; (ii) intensive large scale ap- 
plications; (iii) andosols with high organic matter content and an allophanic microstructure that can trap pollutants. This inertia was assessed by simulating changes in soil CLD contamination using the WISORCH model. Figure 7 shows that one hundred years will be needed to clean up nitisols, and six hundred years to clean up andosols (Cabidoche et al., 2009).
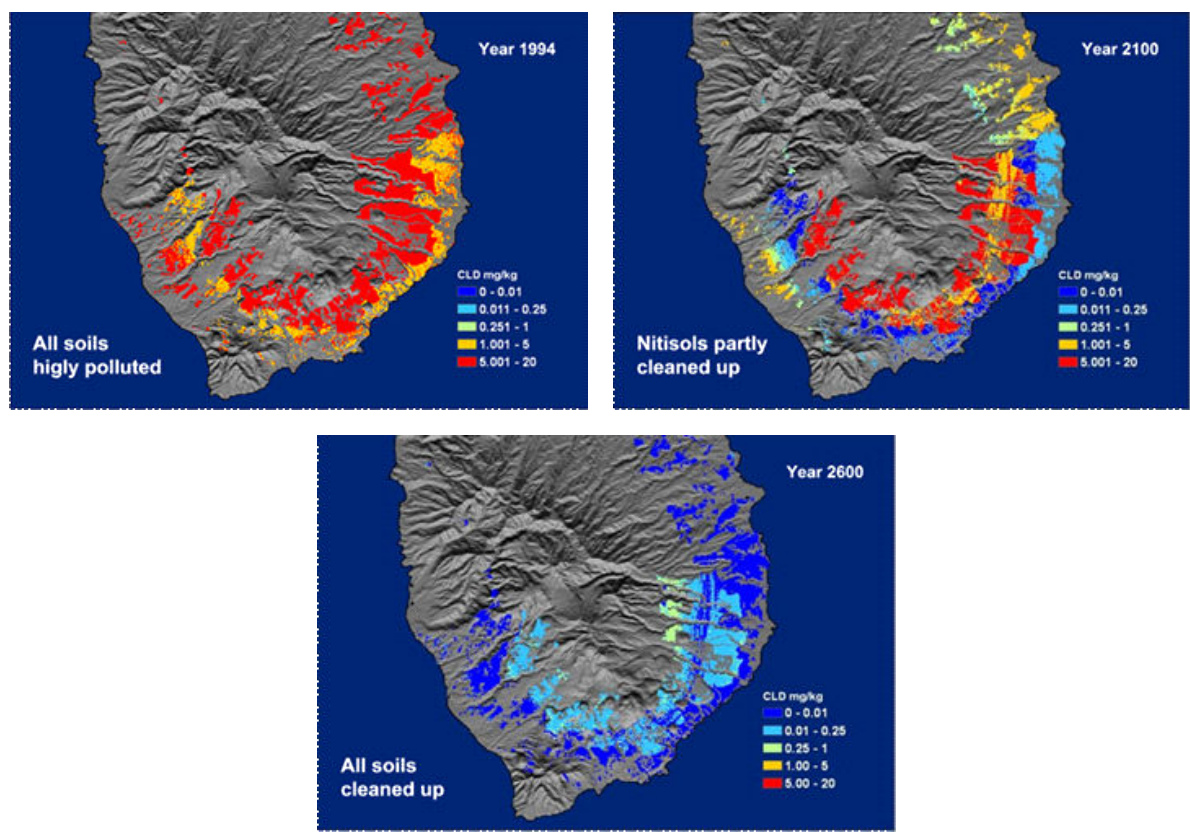

Figure 7. Simulation of changes in soil CLD contamination in Guadeloupe

Figure 7 highlights the need to use different temporal scales to assess pollution: a long term scale when soil retention properties are probably the main explanation for the spatial variability of soil contamination; short and medium term scales when applications of the pollutant explain most spatial variability. From a management point of view, authorities are thus justified in focusing on reducing pollutant loads (the frequency of application and the quantities of pollutant used) on cropped areas, even in the case of less persistent molecules. In the case of CLD, the persistence of pollution calls for further research on soil decontamination. However, in the meantime, different agricultural practices can help manage the risk of contamination, this being the case of soil tillage and organic matter amendment.

\subsection{Tillage practices}

A second step of the diagnosis is the analyses of soil tillage The heterogeneity of CLD content at field scale and the effect of tillage were investigated [33]. 
In the French West Indies, different tillage practices are used on banana plantations. These range from no tillage, especially on sloping plots, to regular deep tillage to a depth of $60 \mathrm{~cm}$ or more, every four years $[10,45]$. The mode of application of the pesticide (powder spread on the ground around the foot of the banana tree), and the semi-perennial arrangement of trees [46] account for the high heterogeneity observed at field scale. Indeed in our study, in the same plot, CLD contamination of the upper soil layer $(0-30 \mathrm{~cm})$ could range from 0.2 to $2.7 \mathrm{mg} \mathrm{kg}^{-1}$ and, in plots of less than $1 \mathrm{ha}$, from 2.9 to $17.6 \mathrm{mg} \mathrm{kg}^{-1}$.

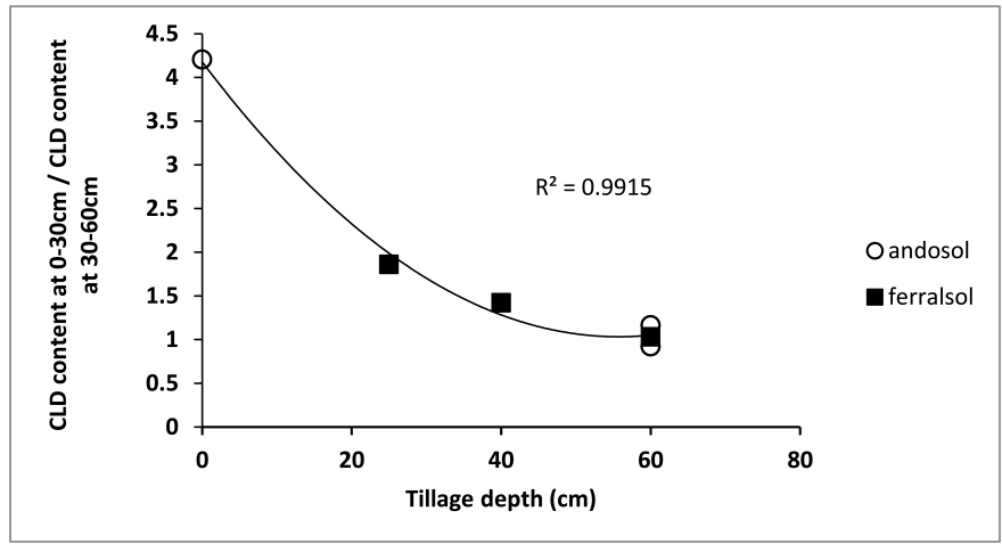

Figure 8. Ratio of CLD contents in the $0-30 \mathrm{~cm}$ and $30-60 \mathrm{~cm}$ soil layers as a function of the depth of tillage, adapted from [33].

Figure 8 shows that, whatever the soil type, the upper soil layer $(0-30 \mathrm{~cm})$ was generally more contaminated than the lower layer $(30-60 \mathrm{~cm})$. With no tillage, the 0-30 cm layer was four times more contaminated than the 30-60 cm layer $\left(21 \mathrm{mg} \mathrm{kg}^{-1}\right.$ and $\left.5 \mathrm{mg} \mathrm{kg}^{-1}\right)$. We also showed that tillage had a significant effect $(\mathrm{P}<0.0001)$ on the horizontal distribution of the contaminant, leading to pesticide dilution in the soil profile. With deep tillage $(60 \mathrm{~cm}$ and deeper), whatever the type of soil and mean CLD content, CLD content was similar at the two sampling depths, with mean values of $11 \mathrm{vs} .12 \mathrm{mg} \mathrm{kg}^{-1}, 12 \mathrm{vs} .11 \mathrm{mg} \mathrm{kg}^{-1}$ and $2 \mathrm{vs} .2 \mathrm{mg}$ $\mathrm{kg}^{-1}$. Thus CLD content was homogenized in the $0-60 \mathrm{~cm}$ layer. In plots where tillage was shallower, the upper layer was still significantly more contaminated than the lower layer although the proportion depended on the tillage depth. This result is in accordance with results observed for DDT [47].

Likewise, tillage tended to reduce CLD horizontal heterogeneity. For this reason, when sampling soil, it is important to take such heterogeneity into account at intra-field scale for accurate assessment of CLD content. For sampling, it is recommended to subdivide all plots of more than 2 ha and, more generally, to use an appropriate sampling procedure that takes into account landscape (slope and resulting erosion), field history (tillage, cropping system, former inter-row distance, etc.) but also the reasons for sampling: cropping system management or analysis of overall risk. 
Tillage is of major concern because it modifies the vertical distribution of the pollutant within the soil profile, and hence the volume of soil that is contaminated and the level of contamination. The risk of the pollutant being transferred to the crop depends on the type of soil and soil CLD content $[19,26]$. Thus, in some cases (mainly low soil CLD content), this will determine the range of crops that can be cultivated while respecting regulatory thresholds, in particular the maximum residue limit of $20 \mu \mathrm{g} \mathrm{kg}^{-1}$ fresh matter for food products [23].

It is also important to keep in mind that tillage practices may negatively affect CLD sequestration and distribution. Indeed tillage during the dry season can cause surface desiccation and reduce pore volume, which will irreversibly alter the micro-structure of allophane [45, 48], thus possibly modifying soil CLD sequestration potential. Moreover, inappropriate tillage practices increase the risk of erosion, driving the top soil layer downslope [49] thereby modifying CLD distribution at plot scale, with higher CLD content at the bottom of the slope than at the top [33].

In conclusion, analyzing past and present farming practices provides insight into CLD content and distribution at intra-field scale. These practices can also affect CLD availability by modifying soil retention properties.

\subsection{Pesticide sequestration by compost addition}

The use of soil organic matter to control the environmental mobility and fate of pesticides has already been reported in the literature [50-53]. Here, we propose an alternative strategy which is quite the opposite of total soil decontamination: CLD sequestration enhanced by soil organic amendment. Because CLD is tightly trapped in the soil, an alternative solution to decontamination may be to further increase its sequestration in the soil thereby reducing pesticide diffusion into the environment. This could be a way to reduce further release of CLD from contaminated soils towards other environmental compartments until efficient remediation techniques become available. We now examine the hypothesis that adding organic matter to contaminated soils improves their CLD sequestration ability with the objective not of removing the pesticide from the soil but rather of controlling its release into the environment.

As detailed above, combined with high organic matter content, the microstructure and the large specific surface area of clay favor the accumulation of pollutants in the soil. In allophanic soil, the high CLD content is the result of the combination of CLD's high affinity for the soil organic content and the poor accessibility of CLD into the mesopore structure.

With the aim of preventing consumer exposure, we tested the incorporation of compost in soils as a possible way to reduce plant contamination [34], based on the hypothesis that adding organic matter would improve CLD trapping and thus reduce its bioavailability for crops. We characterized the transfer of CLD from soil to radish, a crop belonging to roots and tubers, a CLD sensitive group. Two months after incorporation of the compost, the contamination of the different plants organs was 3, 15 and 5 times lower in small roots, tubers and leaves, respectively than without added compost (Figure 9.). 


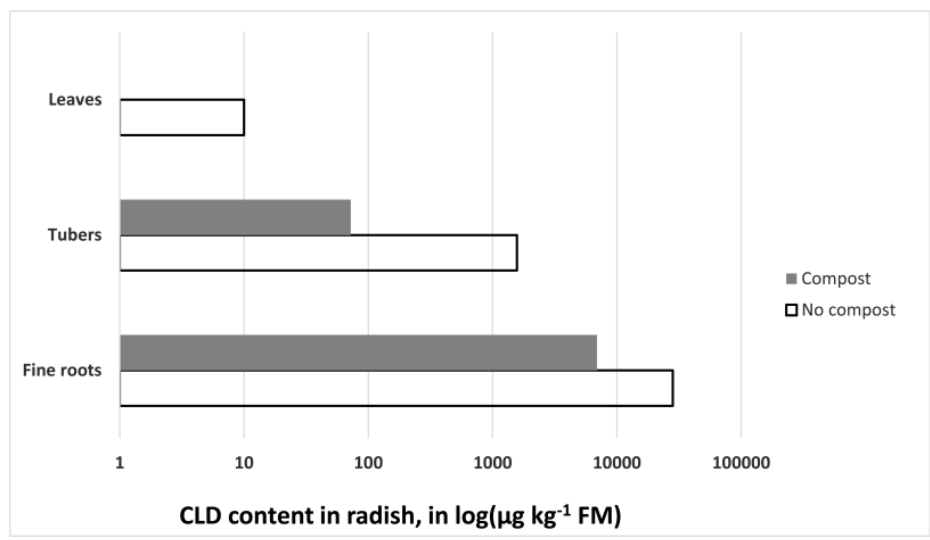

Figure 9. CLD transfer in radish organs (leaves, tubers and fine roots) with added compost (in grey) and without (in white).

These experiments also showed that adding compost closed the microstructure of allophane clays, thus favouring CLD retention in allophanic soils. Adding compost altered the porosity of the allophane clay in the size range 10 to $60 \mathrm{~nm}$, while the intensity of this effect varied with the allophane content. We suggest that these pore changes are the consequence of capillary stress and of the low mechanical properties of the fractal structure [54].

Organic matter (OM) amendments aim to modify chemical conditions within the soil profile. As mentioned above, the OM soil status influences the availability of the pollutant, a factor of primary importance for both pollutant transfer and degradation [55]. At field scale, $\mathrm{OM}$ amendments modify the potential sequestration of persistent organic pollutants in the soil by enhancing the soil's sorption capacity for CLD [56]. This sorption capacity depends on the quantity of OM supplied, the type of OM (stable vs. labile) and the frequency of the application. This practice needs to be studied over time, as OM degrades and could modify the $\mathrm{OM}$ - pollutant relationships.

Finally, all these practices depend on farm strategies. When the aim is to modify these practices, both the scale and the type of farm need to be taken into account. In the case of CLD pollution, analyses revealed a strong "farm effect" [10]. A typology should be built including the farms' overall strategy and objectives, the types of crops grown, practices (more or less intensive) and the farms' specific field orientation (how often the land is used for each crop).

\section{Discussion}

When dealing with agricultural soil pollution, two major tasks must be included in the risk and management analysis: the characterization and analysis of soil physical properties and farmers' past and present practices (Figure 10). These two domains provide information on 
the level of soil pollution, on the behavior and fate of the pollutant in the soil, and on its remediation potential.

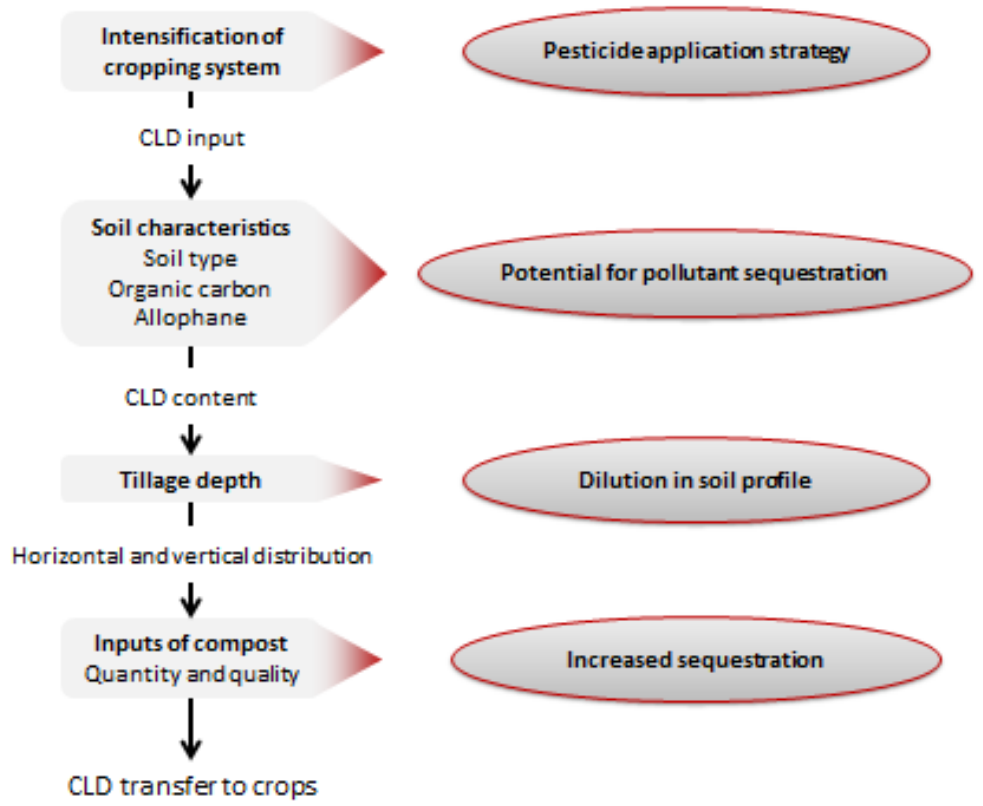

Figure 10. Key determinants of CLD soil pollution.

For soil physical properties, porosity can range from micro-, to meso- and macro-porous in volcanic soils. Fluids containing inorganic and organic solutes and gaseous species can occupy the pores and several factors (size, shape, distribution and connectivity of the pore geometries) determine how fluids migrate into and through the porosity and ultimately adsorb and react with the solid surfaces. The low hydraulic conductivity calculated for fractal allophane aggregates thus explains the high pesticide content of these materials. Because of the resulting low hydraulic conductivity, fluid exchange is slow and pesticide bioavailability is consequently reduced. This leads to the accumulation of pesticides that are not easily chemically or biologically transformed. Future studies on pesticide degrading microorganisms [57] and other bioremediation tools to clean up polluted soils should take the high soil organic carbon content and CLD accessibility in volcanic soils into account.

At field scale, past pesticide application practices account for the potential stock of pollutant in the soil, and an historical analysis will improve the initial diagnosis in terms of the quantity (doses) of pollutant and its horizontal distribution. Modeling and mapping are appropriate tools to roughly simulate current levels of pollution in the field and to identify the parts of a field that contribute to environmental pollution (water, food, animals). Current 
practices explain the diffusion of pollution from the soil reservoir: tillage accounts for the vertical distribution of the pollutant, i.e. dilution of the pollutant in the soil profile, and organic matter amendments account partially for the availability of the pollutant. In this way, current practices modify the level and volume of polluted soil and the environmental state of the field (surface conditions, OM content, soil profile, etc.), which in turn, influence the fate of the pollutant in the environment. Variability among and within farms also needs to be taken into account by building a farm typology including the general orientations and strategies of the farm and farm practices.

Finally, at the regional scale, all these factors combine to determine soil pollution. In the case of CLD, in agreement with the results of physical analyses, andosols, which contain allophanic clay and have high organic matter content, are the most polluted. In addition, the effect of agricultural practices was evidenced by a strong farm effect and an effect of how long the land was used for banana cultivation.

These two aspects (agricultural practices and soil physical properties) proved to be effective in the diagnosis of CLD pollution and in management analysis and could make sense for other forms of agricultural pollution, especially in the case of persistent pesticides. To illustrate this point, the WISORCH model, which accounts for agricultural loads as well as soil and climate characteristics, can simulate changes in soil pollution over time. In the case of CLD contamination, simulation results showed that soils will remain contaminated for six hundred years, with andosols decontaminating at a slower rate than other soils.

\section{Conclusion}

Wide use of chlorinated pesticides such as chlordecone has led to severe contamination of the environment in the French West Indies. Chlordecone is an organochlorine insecticide that was regularly applied to banana crops more than 20 years ago and is now on the list of POPs prohibited by the Stockholm Convention. Chlordecone is a hydrophobic, non-biodegradable pesticide that is strongly bound to the organic soil matrix which is why soils are still contaminated today. The level of soil pollution and the fate of the pollutant in the ecosystems depend on two main determinants at two different scales: agricultural practices and the soil physical properties, i.e. the clay microstructure.

Obviously, the history of agricultural practices (land-use changes and the intensity of pesticide use) partly explains soil contamination. The stocks of pesticide still present in soil are important indicators, which calls for the reinforcement of databases on agricultural practices, especially on pesticide use. However, soil type mainly explains the concentration of pollutant in the soil. Our experimental data showed that clay microstructure controls the accumulation of pollutants in the soil and their release into the environment. In the case of andosols, this study revealed the importance of the fractal microstructure and the associated tortuous porosity in trapping the pollutant. Moreover, as chlordecone tends to bind with soil organic matter, the high organic content of tropical volcanic soils also favors its retention. 
More generally, it is worth noting that since pesticide retention depends on soil type, the concentration of pesticide in the soil cannot provide reliable information about the actual risk of contamination from the soil to the ecosystem. This makes mapping contamination hazards problematic because there is no univocal relation between soil pollution and its capacity to contaminate crops. Additional studies are thus necessary to characterize the behavior of pesticides in soils and to identify the link with plant absorption. This will increase the relevance of mapping pesticide contamination and availability

Concerning possible soil decontamination procedures, the efficiency of chemical or biological species able to degrade the pesticide will be controlled by the microstructure of the clays. Future research into pesticide degrading microorganisms and other remediation tools that could be used to clean up polluted soils should take the accessibility of the pesticide in the soil microstructure into account.

\section{Acknowledgements}

Funding was provided by the French Chlordecone National Plan ("JAFA" project), the French National Research Agency ("Chlordexco" project) and the French Ministry for Overseas development (MOM).

\section{Author details}

T. Woignier ${ }^{1,2^{*}}$, F. Clostre ${ }^{3,4}$, P. Cattan ${ }^{5}$, J. Levillain ${ }^{5}$, Y.M. Cabidoche ${ }^{6}$ and

M. Lesueur-Jannoyer ${ }^{3,4}$

*Address all correspondence to: thierry.woignier@imbe.fr

1 CNRS UMR 7263- Institut Méditerranéen de Biodiversité et d'Ecologie marine et continentale (IMBE), Aix-Marseille Université, Faculté de St-Jérôme, Marseille, France

2 IRD UMR 237- Campus Agro Environnemental Caraïbes, Le Lamentin, Martinique

3 Cirad UR HortSys, TA B-103/PS4, Montpellier, France

4 Cirad/PRAM, UPR HortSys Agroecological Functioning and Performances of Horticultural Cropping Systems, Le Lamentin, Martinique

5 Cirad UPR Banana, Plantain and Pineapple Cropping Systems, Guadeloupe, France

6 Inra ASTRO (TROpicalAgroSystems) Research Unit, Domaine Duclos, Guadeloupe, France 


\section{References}

[1] Cabidoche YM, Achard R, Cattan P, Clermont-Dauphin C, Massat F, Sansoulet J. Long-term pollution by chlordecone of tropical volcanic soils in the French West Indies: A simple leaching model accounts for current residue. Environmental Pollution. 2009;157(5):1697-705.

[2] Coat S, Monti D, Legendre P, Bouchon C, Massat F, Lepoint G. Organochlorine pollution in tropical rivers (Guadeloupe): Role of ecological factors in food web bioaccumulation. Environmental Pollution. 2011;159(6):1692-701.

[3] Luellen DR, Vadas GG, Unger MA. Kepone in James River fish: 1976-2002. Science of the Total Environment. 2006;358(1-3):286-97.

[4] Roche H, Salvat B, Ramade F. Assessment of the pesticides pollution of coral reefs communities from French Polynesia. Revue d'écologie. 2011;66(1):3-10.

[5] Wei S, Lau RKF, Fung CN, Zheng GJ, Lam JCW, Connell DW, et al. Trace organic contamination in biota collected from the Pearl River Estuary, China: A preliminary risk assessment. Marine Pollution Bulletin. 2006;52(12):1682-94.

[6] Epstein SS. Kepone-Hazard evaluation. Science of the Total Environment. 1978;9(1): $1-62$.

[7] Dawson GW, Weimer WC, Shupe SJ. Kepone: a case study of a persistent material. Water American Institute of Chemical Engineers. 1979;Symposium Series 75(190): 366-74.

[8] Kenaga EE. Predicted bioconcentration factors and soil sorption coefficients of pesticides and other chemicals. Ecotoxicology and Environmental Safety. 1980;4(1):26 - 38.

[9] Jablonski PE, Pheasant DJ, Ferry JG. Conversion of Kepone by Methanosarcina thermophila. FEMS Microbiology Letters. 1996;139(2-3):169-73.

[10] Levillain J, Cattan P, Colin F, Voltz M, Cabidoche Y-M. Analysis of environmental and farming factors of soil contamination by a persistent organic pollutant, chlordecone, in a banana production area of French West Indies. Agriculture, Ecosystems \& Environment. 2012;159(0):123-32.

[11] Gourcy L, Baran N, Vittecoq B. Improving the knowledge of pesticide and nitrate transfer processes using age-dating tools $(\mathrm{CFC}, \mathrm{SF} 6,3 \mathrm{H})$ in a volcanic island (Martinique, French West Indies). Journal of Contaminant Hydrology. 2009;108(3-4 ):p. 107-17.

[12] Jondreville C, Bouveret C, Lesueur-Jannoyer M, Rychen G, Feidt C. Relative bioavailability of tropical volcanic soil-bound chlordecone in laying hens (Gallus domesticus). Environ Sci Pollut Res Int. 2012. 
[13] Boucher O, Simard M-N, Muckle G, Rouget F, Kadhel P, Bataille H, et al. Exposure to an organochlorine pesticide (chlordecone) and development of 18-month-old infants. NeuroToxicology. 2013;35(0):162-8.

[14] Dallaire R, Muckle G, Rouget F, Kadhel P, Bataille H, Guldner L, et al. Cognitive, visual, and motor development of 7-month-old Guadeloupean infants exposed to chlordecone. Environmental Research. 2012;118(0):79-85.

[15] Multigner L, Ndong JR, Giusti A, Romana M, Delacroix-Maillard H, Cordier S, et al. Chlordecone Exposure and Risk of Prostate Cancer. Journal of Clinical Oncology. 2010;28(21):3457-62.

[16] Brunet D, Woignier T, Lesueur-Jannoyer M, Achard R, Rangon L, Barthès BG. Determination of soil content in chlordecone (organochlorine pesticide) using near infrared reflectance spectroscopy (NIRS). Environmental Pollution. 2009;157(11):3120-5.

[17] Kumar M, Philip L. Adsorption and desorption characteristics of hydrophobic pesticide endosulfan in four Indian soils. Chemosphere. 2006;62(7):1064-77.

[18] Wang T-Y, Lu Y-L, Dawson RW, Shi Y-J, Zhang H, Xing Y. Effects of Environmental Factors on Organochlorine Pesticide Residues in Soils of the Guanting Reservoir Area, China. Journal of Environmental Science and Health, Part B. 2006;41(3):309-21.

[19] Cabidoche YM, Lesueur-Jannoyer M. Contamination of Harvested Organs in Root Crops Grown on Chlordecone-Polluted Soils. Pedosphere. 2012;22(4):562-71.

[20] Adachi Y, Karube J. Application of a scaling law to the analysis of allophane aggregates. Colloids and Surfaces A Physicochemical and Engineering Aspects. 1999;151(1-2):43-7.

[21] Chevallier T, Woignier T, Toucet J, Blanchart E, Dieudonné P. Fractal structure in natural gels: effect on carbon sequestration in volcanic soils. Journal of Sol-Gel Science and Technology. 2008;48(1):231-8.

[22] Wada K. The distinctive properties of Andosol. Advances in soil science. 1985.

[23] Lesueur-Jannoyer M, Cattan P, Monti D, Saison C, Voltz M, Woignier T, et al. Chlordecone in French West Indies: cropping system changes and their incidence on pollution dispersion. Agronomie Environnement \& Sociétés. 2012;2(1):45-58.

[24] Denaix L, Lamy I, Bottero JY. Structure and affinity towards $\mathrm{Cd} 2+, \mathrm{Cu} 2+, \mathrm{Pb} 2+$ of synthetic colloidal amorphous aluminosilicates and their precursors. Colloids and Surfaces A: Physicochemical and Engineering Aspects. 1999;158(3):315-25.

[25] Teixeira J. Small angle scattering by fractal systems. Journal of Applied Crystallography. 1988;21:781-5.

[26] Woignier T, Clostre F, Macarie H, Jannoyer M. Chlordecone retention in the fractal structure of volcanic clay. Journal of Hazardous Materials. 2012;241-242(0):224-30. 
[27] Martin-Laurent F, Sahnoun M, Merlin C, Vollmer G, Lübke M. Detection and quantification of chlordecone in contaminated soils from the French West Indies by GC-MS using the 13C10-chlordecone stable isotope as a tracer. Environmental Science and Pollution Research. 2013:1-6.

[28] Brinker CJ, Scherer GW. Sol-gel science: the physics and chemistry of sol-gel processing: Academic Press; 1990. 908 p.

[29] Topp E, I. S, Attar A, Korte F. Factors affecting the uptake of 14C-labeled organic chemicals by plants from soil. Ecotoxicology and Environmental Safety. 1986;11(2): $219-28$.

[30] George SE, Claxton LD. Biotransformation of chlordecone by Pseudomonas species. Xenobiotica the fate of foreign compounds in biological systems. 1988;18(4):407-16.

[31] Orndorff SA, Colwell RR. Microbial transformation of kepone. Applied and Environmental Microbiology. 1980;39(2):398-406.

[32] Mouvet C, Bristeau S, Amalric L, Dictor MC, Mercier A, Thannberger L, et al., editors. In Situ Chemical Reduction (ISCR) for Removal of Persistent Pesticides; focus on kepone in tropical soils. International Symposium on Bioremediation and sustainable Environmental Technologies; 2011 Jun; Reno, États-Unis.

[33] Clostre F, Lesueur-Jannoyer M, Achard R, Letourmy P, Cabidoche Y-M, Cattan P. Decision support tool for soil sampling of heterogeneous pesticide (chlordecone) pollution. Environmental Science and Pollution Research. 2013:1-13.

[34] Woignier T, Fernandes P, Jannoyer-Lesueur M, Soler A. Sequestration of chlordecone in the porous structure of an andosol and effects of added organic matter: an alternative to decontamination. European Journal of Soil Science. 2012;63(5):717-23.

[35] Biarnès A, Rio P, Hocheux A. Analyzing the determinants of spatial distribution of weed control practices in a Languedoc vineyard catchment. Agronomie. 2004;24(4): 187-96.

[36] Houdart M. Spatial organisation of agricultural activities and water pollution by pesticides Modelling in Capot's watershed, Martinique (French West Indies). Martinique: UAG; 2006.

[37] Nkamleu GB, Adesina AA. Determinants of chemical input use in peri-urban lowland systems: bivariate probit analysis in Cameroon. Agricultural Systems. 2000;63(2):111-21.

[38] Blazy J-M, Ozier-Lafontaine H, Doré T, Thomas A, Wery J. A methodological framework that accounts for farm diversity in the prototyping of crop management systems. Application to banana-based systems in Guadeloupe. Agricultural Systems. 2009;101(1-2):30-41. 
[39] de Barros I, Blazy JM, Rodrigues GS, Tournebize R, Cinna JP. Emergy evaluation and economic performance of banana cropping systems in Guadeloupe (French West Indies). Agriculture, Ecosystems \& Environment. 2009;129(4):437-49.

[40] Duyck P-F, Lavigne A, Vinatier F, Achard R, Okolle JN, Tixier P. Addition of a new resource in agroecosystems: Do cover crops alter the trophic positions of generalist predators? Basic and Applied Ecology. 2011;12(1):47-55.

[41] Mollot G, Tixier P, Lescourret F, Quilici S, Duyck P-F. New primary resource increases predation on a pest in a banana agroecosystem. Agricultural and Forest Entomology. 2012;14(3):317-23.

[42] Woignier T, Braudeau E, Doumenc H, Rangon L. Supercritical Drying Applied to Natural "Gels": Allophanic Soils. Journal of Sol-Gel Science and Technology. 2005;36(1):61-8.

[43] Desprat J-F, Comte J-P, Chabrier C. Cartography of soil pollution risk through organochlorine in Martinique. Technical report Phase3: Synthesis. 2004 Contract No.: BRGM/RP53262-FR.

[44] Tillieut O, Cabidoche Y-M. Cartography of soils CLD pollution in Guadeloupe. Technical report. Abymes, France: DAAF-SA \& INRA-ASTRO, 2006.

[45] Clermont-Dauphin C, Cabidoche YM, Meynard JM. Effects of intensive monocropping of bananas on properties of volcanic soils in the uplands of the French West Indies. Soil Use and Management. 2004;20(2):105-13.

[46] Cattan P, Voltz M, Cabidoche YM, Lacas JG, Sansoulet J. Spatial and temporal variations in percolation fluxes in a tropical Andosol influenced by banana cropping patterns. Journal of Hydrology. 2007;335(1-2):157-69.

[47] Spencer WF, Singh G, Taylor CD, LeMert RA, Cliath MM, Farmer WJ. DDT Persistence and Volatility as Affected by Management Practices after 23 Years. J Environ Qual. 1996;25(4):815-21.

[48] Dorel M, Roger-Estrade J, Manichon H, Delvaux B. Porosity and soil water properties of Caribbean volcanic ash soils. Soil Use and Management. 2000;16(2):133-40.

[49] Perret S, Dorel M. Relationships between land use, fertility and Andisol behaviour: examples from volcanic islands. Soil Use and Management. 1999;15(3):144-9.

[50] Ahmad R, Kookana RS, Alston AM, Skjemstad JO. The nature of soil organic matter affects sorption of pesticides. 1. Relationships with carbon chemistry as determined by C-13 CPMAS NMR spectroscopy. Environmental Science \& Technology. 2001;35(5):878-84.

[51] Fushiwaki Y, Urano K. Adsorption of pesticides and their biodegraded products on clay minerals and soils. Journal of Health Science. 2001;47(4):429-32. 
[52] Kanazawa J. Relationship between the soil sorption constants for pesticides and their physicochemical properties. Environmental Toxicology and Chemistry. 1989;8(6): 477-84.

[53] Li H, Sheng G, Teppen BJ, Johnston CT, Boyd SA. Sorption and Desorption of Pesticides by Clay Minerals and Humic Acid-Clay Complexes. Soil Sci Soc Am J. 2003;67(1):122-31.

[54] Fernandes P, Jannoyer-Lesueur M, Soler A, Achard R, Woignier T. Effects of clay microstructure and compost quality on chlordecone retention in volcanic tropical soils: consequences on pesticide lability and plant contamination. 19th World Congress of Soil Science, Soil Solutions for a Changing World2010. p. 50-3.

[55] AFNOR. Amendements organiques et supports de culture - Caractérisation de la matière organique par fractionnement biochimique et estimation de sa stabilité biologique - Soil improvers and growing media - Characterization of organic matter by biochemical fractioning and estimation of its biological stability. Saint Denis la Plaine, France: AFNOR; 2009. p. 19.

[56] Dolfing J, Novak I, Archelas A, Macarie H. Gibbs free energy of formation of chlordecone and potential degradation products: implications for remediation strategies and environmental fate. Environ Sci Technol. 2012;46(15):8131-9. Epub 2012/07/12.

[57] Dolfing J, Novak I, Archelas A, Macarie H. Gibbs free energy of formation of chlordecone and potential degradation products: implications for remediation strategies and environmental fate. Environ Sci Technol. 2012;46(15):8131-9. Epub 2012/07/12. 